\title{
Successful salvage treatment of peptic duodenal stenosis with repeat insertion of self-expanding stent after failed balloon dilation
}

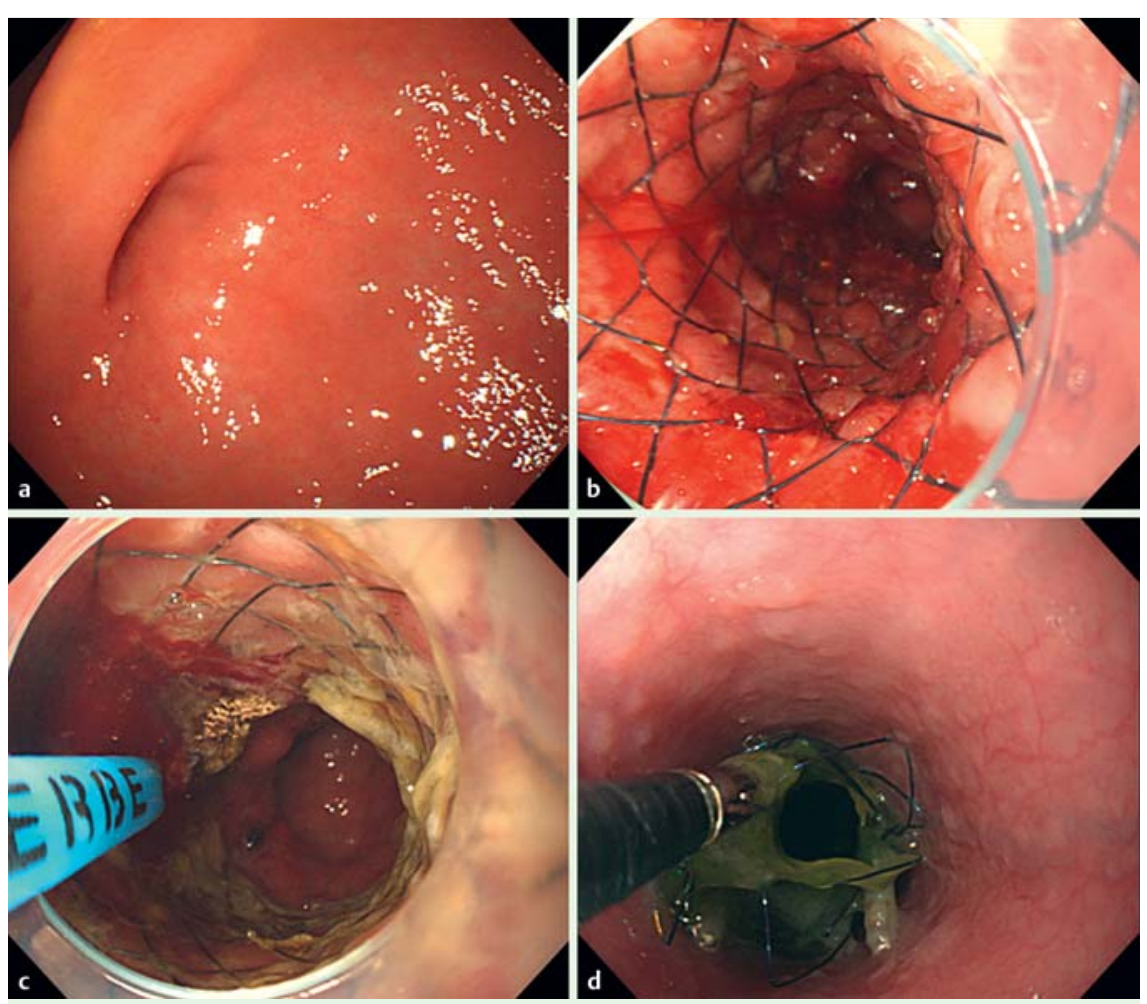

Fig. 1 a Narrowed pyloric outlet due to recurrent duodenal ulcer, precluding passage of an endoscope. b Self-expanding metallic stent (SEMS) inserted using the through-the-scope method. c The SEMS was removed endoscopically and reinserted at 4-8 weeks' intervals. d Tissue growing through the stent mesh was trimmed using argon plasma coagulation (APC), several weeks after stent insertion.

A 63-year-old man attended the hospital due to early satiety and indigestion. He had had peptic ulcer disease for several years and had received proton pump inhibitor (PPI) therapy for a prolonged period at another center without satisfactory outcome. Endoscopic examination revealed a narrowed pyloric channel that precluded passage of a scope ( $\bullet$ Fig. 1 a). Urea breath test result was negative, proving that previous Helicobacter pylori eradication treatment had been successful. To alleviate the patient's symptoms, we carried out repeated endoscopic balloon dilation at 7-10-day intervals, using through-the-scope (TTS) balloon dilation catheters up to $12 \mathrm{~mm}$ diameter. However, after five sessions of this intervention there was no improvement in the symptoms. As the patient did not want to undergo surgery, endoscopic self-expanding metallic stent (SEMS) installation was attempted. A 7-cm, partial covered stent (Hanarostent, M. I. Tech Co., Ltd., Seoul, Korea) was deployed using an endoscope and the TTS method ( Fig. $\mathbf{1} \mathbf{b}$ ). There were no immediate complications and the patient was put on a liquid diet that night. After 2 weeks, follow-up endoscopy revealed a patent stent in a fairly good position. Considering the possibility of in-stent growth of granulation tissue, the stent was removed after the fourth week of insertion via endoscopy with forceps ( $\bullet$ Fig. 1 c). Use of argon plasma coagulation (APC) to ablate the in-growing granulation tissue ( $\bullet$ Fig. 1 d) allowed reinsertion of the SEMS at 4-8 weeks intervals at the endoscopist's discretion. The removal/insertion process was repeated six times. The final endoscopic examination revealed a significantly wider pyloric channel, which allowed easy passage of an endoscope ( $\bullet$ Fig. 2). The patient is

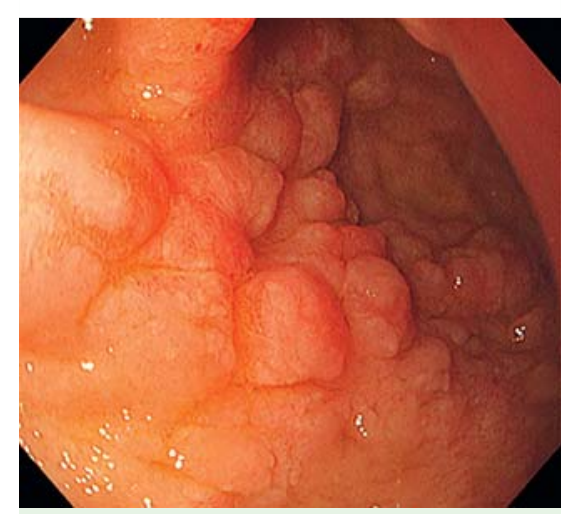

Fig. 2 Previously narrowed pyloric channel showing a significantly larger lumen after six sessions of self-expanding metallic stent insertion-removal.

currently on double doses of PPI, and has had no signs or symptoms of obstruction over 1 year of follow-up.

Endoscopic balloon dilation is a common method for management of benign pyloric stricture [1 - 3], but has been criticized for suboptimal results, repeat procedures, and rare complications such as bowel perforation $[4,5]$. The present case exemplifies endoscopic SEMS insertion as another way for managing benign pyloric strictures, and our patient is the first successful case to be reported. SEMS may be used as a salvage treatment for pyloric stenosis or even as the main intervention. Removal with APC of tissue growing through the stent mesh or over the stent ends also enables prolonged SEMS placement.

Endoscopy_UCTN_Code_TTT_1AO_2AH

\section{Competing interests: None}

S. Park' , H. J. Chun'², B. Keum², B. J. Lee², Y. S. Seo ${ }^{2}$, Y. S. Kim², J. J. Park ${ }^{2}$, Y. T. Jeen ${ }^{2}$, H. S. Lee ${ }^{2}$, S. H. Um², C. D. Kim² ${ }^{2}$ H. S. Ryu ${ }^{2}$

Division of Gastroenterology and Hepatology, Department of Internal Medicine, Hanil General Hospital, KEPCO Medical Foundation, Seoul, Korea

2 Institute of Digestive Disease and Nutrition, Department of Internal Medicine, Korea University College of Medicine,

Seoul, Korea 


\section{References}

1 Kochhar R, Sethy PK, Nagi B, Wig JD. Endoscopic balloon dilatation of benign gastric outlet obstruction. J Gastroenterol Hepatol 2004; 19: 418-422

2 Cherian PT, Cherian S, Singh P. Long-term follow-up of patients with gastric outlet obstruction related to peptic ulcer disease treated with endoscopic balloon dilatation and drug therapy. Gastrointest Endosc 2007; 66: 491 - 497
3 Solt J, Bajor J, Szabo M, Horvath OP. Longterm results of balloon catheter dilation for benign gastric outlet stenosis. Endoscopy 2003; 35: 490-495

4 Lau JY, Chung SC, Sung JJ et al. Through-thescope balloon dilation for pyloric stenosis: long-term results. Gastrointest Endosc 1996; 43: $98-101$

5 Perng CL, Lin HJ, Lo WC et al. Characteristics of patients with benign gastric outlet obstruction requiring surgery after endoscopic balloon dilation. Am J Gastroenterol 1996; 91: 987-990
Bibliography

DOI $10.1055 / \mathrm{s}-0030-1256322$

Endoscopy 2011; 43: E187-E188

(c) Georg Thieme Verlag KG Stuttgart · New York . ISSN 0013-726X

\section{Corresponding author \\ Prof. H. J. Chun}

Department of Internal Medicine, Institute of Digestive Disease and Nutrition

Korea University College of Medicine

Korea University Medical Center

73 Inchon-ro

Seongbuk-Gu

Seoul 136-705

Korea

Fax: +82-2-953-1943

drchunhj@chol.com 